www.jmscr.igmpublication.org

Impact Factor 5.84

Index Copernicus Value: 83.27

ISSN (e)-2347-176x ISSN (p) 2455-0450

crossref DOI: _https://dx.doi.org/10.18535/jmscr/v5i7.56

Journal Of Medical Science And Clinical Research

IGM Publication

An Official Publication of IGM Publication

\title{
Correlation between histology and bleeding pattern in a case of AUB and risk factors analysis of $\mathrm{AUB}$ in reproductive age group
}

\author{
Authors \\ Dr Nidhi Meena ${ }^{1}$, Dr Suman Meena ${ }^{2}$ \\ ${ }^{1}$ MS OBG, Govt. Medical College Kota (Rajasthan) \\ ${ }^{2}$ Assistant professor MS OBG, Govt. Medical College Kota (Rajasthan)
}

\begin{abstract}
Background: Excessive and abnormal menstrual bleeding is the commonest symptom which brings a perimenopausal woman to the hospital. This age group is more amenable to serious conditions like genital cancer; hence this bleeding should be seriously evaluated to exclude the life threatening conditions by easily available investigating modalities like ultrasonography (USG) and biopsy before deciding their line of treatment.

Objective: Analysing the histomorphological pattern of endometrium in abnormal uterine bleeding, Correlation $b / w$ histopathology and bleeding pattern in AUB and to analyse the various risk factors associated with AUB. at a tertiary care centre.

Materials and Methods: The material for the study was collected from the endometrial biopsy samples sent for histopathological examination from clinically diagnosed cases of Abnormal uterine bleeding from OPD, J.K.Lon Women hospital, GMC Kota. This was a prospective study done on patients presenting with AUB from Jan 2015 to Dec 2015 in the Department of Obstetrics \& Gynaecology in collaboration with the department of Pathology of Govt. Medical College Kota, (Rajasthan). The study material included a total number of 100 specimens consisting hysterectomy specimens.

Results: Abnormal uterine bleeding was high in parous women, Grand multipara 38\%, multipara 55\% (P3= 34\%, $P 2=21 \%)$. The majority of the women (49\%) presented with menorrhagia, $26 \%$ with metrorhagia, polymenorrhagia was present in $20 \%$ of cases and Postmenopausal bleeding were seen in 5\% cases. There were $29 \%$ fibroid uterus, Adenomyosis (26\%) and $21 \%$ were diagnosed as DUB, fibroid with adenomyosis in (13\%). Postmenopausal bleeding (5\%) of cases. Endometrial polyp in 3\% Endometrial Carcinoma were seen in 2\% cases and Monckerbergs scleroma were seen in 1 case. Endometrium was Secretory in 66\%, Proliferative (10\%). Atrophic endometrium (9\%). Endometrial hyperplasia (7\%), endometrial malignancy (2\%), Endometrial polyp (3\%), Chronic endometritis (2\%) and Monckerbergs scleroma was seen in 1\% cases. Multiparity (55\%) and grand multiparity (38\%) was the major risk factors for AUB followed by hypertension (21\%), PID (19\%) Diabetes (12\%), Obesity (4\%) and tuberculosis is found in $1 \%$ case. There is significant correlation between Parity and Bleeding pattern (Coefficient of Correlation $(r)=+0.896)$. There is significant correlation between Endometrial histopathological finding and Bleeding pattern (Coefficient of Correlation $(r)=+0.98$ )

Conclusion: Abnormal uterine bleeding predominantly affects women of perimenopuasal age group which needs thorough evaluation as it could be the only clinical manifestation of endometrial cancer. In our study, Organic causes were found to be the commonest cause of abnormal uterine bleeding followed by dysfunctional uterine bleeding. All these women underwent dilatation \& curettagel endometrial biopsy or hysterectomy depending on the diagnosis.
\end{abstract}

Keywords: Dysfunctional Uterine Bleeding $\cdot$ Leiomyoma $\cdot$ Adenomyosis $\cdot$ Endometriosis $\cdot$ Endometrial Hyperplasia. 


\section{Introduction}

Abnormal uterine bleeding is considered as one of the most common and challenging problem presenting to the gynaecologist. It is responsible for as many as one-third of all outpatient gynaecological visits ${ }^{(1,2)}$.

Abnormal uterine bleeding include both dysfunctional uterine bleeding and bleeding from structural causes like fibroids, polyps and endometrial carcinoma ${ }^{(3)}$.

Endometrium is a dynamic, hormonally sensitive and responsive tissue which constantly and rhythmically undergoes changes in the active reproductive life. Abnormal uterine bleeding (AUB) may be defined as a bleeding pattern that differs in frequency, duration and amount from a pattern observed during a normal menstrual cycle or after menopause ${ }^{(4)}$.

Dysfunctional uterine bleeding is defined as abnormal uterine bleeding without a demonstrable organic cause ${ }^{(5)}$. It may be anovulatory characterised by irregular, unpredictable bleeding (metro-rhagia) or ovulatory resulting in heavy but regular periods (menorrhagia) ${ }^{(6)}$.

AUB is one of the most common problems in women of all ages especially those in the perimenopausal age group thus it is affecting the women to that extent, that their day to day life is being disturbed. The abnormal bleeding can be caused by a wide variety of disorders and it is one of the commonest complaint leading to endometrial sampling.

According to RCOG guidelines, endometerial biopsy should be performed on all women over 35 years with menorrhagia to rule out endometrial cancer or pre-malignant lesion (e.g atypical hyperplasia). Endometrial biopsy also should be considered in women between the age 18 and 35 years with AUB who have risk factors for endometrial cancer or if AUB does not resolve with medical management ${ }^{(7)}$.

AUB may be the symptom of endometrial carcinoma in $8-50 \%$ of cases $^{(8)}$. Adenocarinoma of the endometrium is often preceded by proliferative precursor lesions "endometrial hyperplasia". Thus, early accurate diagnosis and proper treatment of endometrial hyperplastic lesions are essential to prevent progress to endometrial cancer and preclude unwarranted hysterectomy without definitive diagnosis ${ }^{(9)}$.

\section{Aims And Objective}

1. Analysing the histomorphological pattern of endometrium in abnormal uterine bleeding.

2. Correlation $b / w$ histopathology and bleeding pattern in AUB.

3. To analyse the various risk factors associated with AUB.

\section{Material and Method}

Source of data- The material for the study was collected from the endometrial biopsy samples sent for histopathological examination from clinically diagnosed cases of Abnormal uterine bleeding from OPD, J.K.Lon Women hospital, GMC Kota.

\section{Sample size: 100}

\section{Duration of the study: 1 year}

Methods of collection of data- This was a prospective study done on patients presenting with AUB from Jan 2015 to Dec 2015 in the Department of Obstetrics \& Gynaecology in collaboration with the department of Pathology of Govt. Medical College Kota, (Rajasthan). Patients were selected based on clinical details, from Gynae OPD. Patient was thoroughly evaluated by history taking and detailed examination and a predesigned performa was filled for each patient. The study material included a total number of 100 specimens consisting hysterectomy specimens, endometrial sampling done by endometrial biopsy and sent to Pathology department.

Inclusion Criteria- Endometrial biopsy samples of clinically diagnosed cases of abnormal uterine bleeding of patients (in age group 25- 50 years age) were included in the study.

Exclusion Criteria- Endometrial biopsy samples of clinically diagnosed cases of abnormal uterine 
bleeding of patients more than 50 years age and < 25 year were excluded from the study.

\section{Result and Analysis}

Abnormal uterine bleeding was high in parous women, Grand multipara 38\%, multipara 55\% $(\mathrm{P} 3=34 \%, \mathrm{P} 2=21 \%)$. This shows incidence of abnormal uterine bleeding increases as the parity increases.

The majority of the women (49\%) presented with menorhagia, $26 \%$ with metrorhagia, polymenorrhagia was present in $20 \%$ of cases and Postmenopausal bleeding were seen in $5 \%$ cases.

There were 29\% fibroid uterus, Adenomyosis was diagnosed in $26 \%$ and $21 \%$ were diagnosed as DUB., fibroid with adenomyosis in $13 \%$ of cases. Postmenopausal bleeding was seen in $5 \%$ of cases. Endometrial polyp in 3\% Endometrial Carcinoma were seen in $2 \%$ cases and Monckerbergs scleroma were seen in 1 case.

Histopathological reports revealed that endometrium was Secretory in $66 \%$ and Proliferative in $10 \%$. Atrophic endometrium was seen in $9 \%$. Endometrial hyperplasia was seen in $7 \%$ of cases and endometrial malignancy in $2 \%$, Endometrial polyp in 3\%. Chronic endometritis was seen in $2 \%$ of cases and Monckerbergs scleroma was seen in $1 \%$ cases.

Multiparity (55\%) and grand multiparity (38\%) was the major risk factors for AUB followed by hypertension (21\%), PID (19\%) Diabetes (12\%), Obesity (4\%) and tuberculosis is found in $1 \%$ case. Bleeding disorders was not found in any of the cases.

There is significant correlation between Parity and Bleeding pattern (Coefficient of Correlation (r) = +0.896).

There is significant correlation between Endometrial histopathological finding and Bleeding pattern (Coefficient of Correlation $(r)=$ +0.98 )

The following tables and figures illustrate the results in detail.
Table (1) Histopathological finding of Endometrium $(\mathrm{n}=100)$

\begin{tabular}{|l|c|c|}
\hline Histopathological finding & No. Of Cases & Percentage \\
\hline Secretory phase & 66 & $66 \%$ \\
\hline Proliferative Phase & 10 & $10 \%$ \\
\hline Atrophied & 9 & $9 \%$ \\
\hline Hyperplasia & 7 & $7 \%$ \\
\hline Malignancy & 2 & $2 \%$ \\
1.Malignant mixed mullerian tumor & 1 & $1 \%$ \\
2.Mucinous Adenocarcinoma & 1 & $3 \%$ \\
\hline Endometrial Polyp & 3 & $2 \%$ \\
\hline Chronic Endometritis & 2 & $1 \%$ \\
\hline Monckerbergs scleroma & 1 & $100 \%$ \\
\hline Total & 100 & \\
\hline
\end{tabular}

Table-(2) Correlation of Bleeding Pattern with Endometrial Histopathology

\begin{tabular}{|c|c|c|c|c|c|}
\hline \multirow{2}{*}{$\begin{array}{l}\text { Endometrial } \\
\text { Histopathology }\end{array}$} & \multicolumn{4}{|c|}{ Bleeding Pattern $(n=100)$} & \multirow{2}{*}{$\begin{array}{l}\text { Tota } \\
1\end{array}$} \\
\hline & $\begin{array}{l}\text { Menorrh } \\
\text { agia }\end{array}$ & $\begin{array}{l}\text { Metrorrha } \\
\text { gia }\end{array}$ & $\begin{array}{l}\text { Polymen } \\
\text { orrhea }\end{array}$ & $\begin{array}{l}\text { Postmeno } \\
\text { pausal }\end{array}$ & \\
\hline Secretory & 31 & 15 & 16 & 4 & 66 \\
\hline Proliferative & 6 & 4 & 0 & 0 & 10 \\
\hline Atrophic & 7 & 2 & 0 & 0 & 9 \\
\hline Hyperplasia & 2 & 3 & 2 & 0 & 7 \\
\hline Others & 3 & 2 & 2 & 1 & 8 \\
\hline Total & 49 & 26 & 20 & 5 & 100 \\
\hline
\end{tabular}

Table- (3) Risk Factors For AUB ( $\mathrm{n}=100)$

\begin{tabular}{|l|c|c|}
\hline Risk Factor & No. Of Cases & Percentage \\
\hline Multiparity & 55 & $55 \%$ \\
\hline Grand Multiparity & 38 & $38 \%$ \\
\hline Hypertension & 21 & $21 \%$ \\
\hline PID & 19 & $19 \%$ \\
\hline Diabetes & 12 & $12 \%$ \\
\hline Obesity & 4 & $4 \%$ \\
\hline Tuberculosis & 1 & $0 \%$ \\
\hline Bleeding Disorders & 0 & $1 \%$ \\
\hline
\end{tabular}

\section{Discussion}

The common cause of AUB was Fibroid in our study which was $29 \%$. The second most common cause of AUB was found to be Adenomyosis of uterus which was $26 \%$ followed by DUB (21\%), Fibroid with adenomyosis in $13 \%$ followed by Postmenopausal bleeding in 5\%,Endometrial polyp and Endometrial carcinoma 3\% each. Similar results were seen in study done by Yogesh Neena et al ${ }^{(12)}$. Perveen and Tayyab reviewed 54 elective abdominal hysterectomies and revealed 
that menstrual disturbance/ DUB is a leading indication $(27.7 \%)$ of hysterectomy and leiomyoma is the commonest (59. 2\%) pathological lesion ${ }^{(19)}$.

Commonest bleeding pattern in my study was found to be menorrhagia (49\% cases). Similar results were seen in study conducted by Sweta Agrawal et al (49\%) ${ }^{(21)}$, Ara and Roohi $(49.06 \%)$ ${ }^{(22)}$, Zeeba et al $(41 \%)^{(10)}$, Naheed moghal et al $(41 \%)^{(11)}$, Prasad usha et al $(62.6 \%)^{(13)}$, Ayesha sarwar et al $(30 \%)^{(15)}$, Dr. Usha G. Doddamanni et al $(45.5 \%)^{(18)}$ and Bhatta S. Et al (30.32) ${ }^{(17) .}$

Metrorrhagia was present in $26 \%$ of cases in our study. Similar results were seen in study conducted by Zeeba et al $(25 \%)^{(10)}$, Dr. Usha G. Doddamani $(28.2 \%)^{(18)}$ and Bhatta S. Et al $(38.52 \%)^{(17)}$, Sweta Agrawal et al $(16.75 \%)^{(22)}$. higher results were seen in study conducted by Naheed Moghal et al(48\%) $)^{(11)}$.

Polymenorrhea was present in $20 \%$ cases in our study. Similar results were seen in study conducted by Dr. Usha G. Doddamani $(20 \%)^{(18)}$, Prasad Usha et al $(8.24 \%)^{(13)}$, Naheed Moghal et $\operatorname{al}(8 \%)^{(11)}$.

Postmenopuasal bleeding was seen in 5\% cases similar results were seen in study conducted by Dr. Usha G. Doddamani $(5.8 \%)^{(18)}$ Naheed Moghal et al $(6 \%)^{(11)}$, Ara $\mathrm{S}$ and Roohi $\mathrm{M}$ $(6.86 \%)^{(22)}$, Upadhyaya and Malla $(6.6 \%)$, Prasad Usha et al $(8.52 \%)^{(13)}$. Higher results were seen in study conducted by Bhatta $\mathrm{S}$ et al $(30 \%)^{(17)}$, Ayesha Sarwar et al $(10 \%)^{(15)}$ and Sweta Agrawal et al $(10 \%)^{(21)}$

In our study Fibroid was diagnosed in $29 \%$ of AUB \& Adenomyosis in $26 \%$ of cases. DUB was seen in $21 \%$ of cases. These results were comparable to study conducted by Bhosle et al. ${ }^{(20)}$, Dr. Usha G et al ${ }^{(18)}$.

In the present study, most common Endometrial histopathology is secretory (66\% cases). Similar results were seen in study conducted by Prasad Usha et al $(56.2 \%)^{(13)}$, lower incidence were seen in study conducted by Zeeba $\mathrm{S}$ et al $(28.99 \%)^{(10)}$, Saraswathi Doraiswami et al $(28.45 \%)^{(14)}$, Dr. Usha G. Dodamani $(23.5 \%)^{(18)}$.
Proliferative endometrium was seen in $10 \%$ cases. This finding is similar to other studies Saraswathi Doraiswami et al $(20.5 \%)^{(14)}$, Higher results were seen in studies conducted by Zeeba $\mathrm{s}$ et $\operatorname{al}(24.92)^{(10)}$, Bhatta $S$ et al $(26.23 \%)^{(17)}$, Prasad Usha et al $(28.83 \%)^{(13)}$, Dr. Usha G. Dodamani $(44.7 \%)^{(18)}$.

Endometrial hyperplasia is a precursor of endometrial cancer. The incidence of endometrial hyperplasia without and with atypia peaks in early 50 's and early 60's respectively. The incidence of endometrial hyperplasia in our study was $7 \%$ which was almost comparable with study conducted by Prasad Usha et al $(6.86 \%)^{(13)}$. Saraswathi Doraiswami et al $(6.1 \%)^{(14)}$, Zeeba S. Jairajpuri et al $(8 \%)^{(10)}$, Sweta Agrawal et al $(20.75 \%)^{(21)}$,

The incidence of Atrophic endometrium was $9 \%$ in our study and similar results were seen in study conducted by Bhatta S et al $(7.38 \%)^{(17)}$, Dr. Usha G. Dodamani $(5.8 \%)^{(18)}$. Lower incidence were seen in study conducted by Naheed Moghal et al $(1.3 \%)^{(11)}$. Higher incidence were seen in a study conducted by Prasad Usha et al $(13.73 \%)^{(13)}$.

Chronic Endometritis was in $2 \%$ cases in our study and similar results were seen in study conducted by Naheed Moghal et al (3.28\%) ${ }^{(11)}$, Yogesh Neena $(3.47 \%)^{(12)}$, Saraswathi Doraiswami et al $(4.25 \%)^{(14)}$ where as it was higher in study conducted by Prasad Usha et al $(6 \%)^{(13)}$, Dr. Usha G. Dodamani $(9.4 \%)^{(18)}$.

Endometrial Carcinoma was seen in $2 \%$ cases $(1 \%$ Malignant mixed mullerian tumor and $1 \%$ Mucinous Adenocarcinoma), similar results were seen in study conducted by Zeeba S. et al $(2 \%)^{(10)}$, Ayesha Sarwar and Anwar ul Haque (2\%) ${ }^{(15)}$, Nadia Adnan Ghani $(2.1 \%)^{(16)}$, Prasad Usha et al $(0.86 \%)^{(13)}$, Naheed Moghal et al $(3 \%)^{(11)}$.

Endometrial polyp in my study was $3 \%$ cases, similar results were seen in study conducted by Bhatta $\mathrm{S}$ et al $(2.46 \%)^{(17)}$, Prasad Usha et $\operatorname{al}(1.64 \%)^{(13)}$. Higher incidence of endometrial polyp were seen in study conducted by Saraswathi Doraiswami et al $(11.2 \%)^{(14)}$ and Naheed Moghal et al $(8.95 \%)^{(11)}$. 
Monckerbergs scleroma was seen in $1 \%$ cases in my study and no other study show the same.

Advance age is a major risk factor for AUB, In present study, the maximum incidence of AUB was in the 40-45 years age range (60\% patients) followed by $46-50$ years age group (37\% pateints). High parity is a major risk factor for AUB, The incidence of AUB was high as the parity increases in our study. Similar results were seen in study conducted by Bhosle et al. ${ }^{(20)}$, Dr. Usha G et al ${ }^{(18)}$ Dr. Astha Saheta, Dr.C.Hariharan, Dr.Urvashi Sharma in their study showed that the major risk factors observed were age, parity and menopausal status. The maximum incidence of AUB seen in patients in peri-menopausal age group i.e 36-40 years of age and those who were multiparous ${ }^{(23)}$.

Hypertension was seen in $21 \%$ cases and diabetes was seen in $12 \%$ similar results were seen in study conducted by Anupamasuresh Y, Suresh YV, Prachi Jain found $32.3 \%$ cases had hypertension and $9.2 \%$ cases had diabetes mellitus ${ }^{(24)}$,Sanita Kayastha in her study showed that $15 \%$ had hypertension and $7 \%$ patient had diabetes associaterd with AUB ${ }^{(25)}$.

\section{Conclusion}

Abnormal uterine bleeding predominantly affects women of perimenopuasal age group which needs thorough evaluation as it could be the only clinical manifestation of endometrial cancer.

In our study, Organic causes were found to be the commonest cause of abnormal uterine bleeding followed by dysfunctional uterine bleeding. All these women underwent dilatation \& curettage/ endometrial biopsy or hysterectomy depending on the diagnosis. Histopathology revealed majority of endometrium in secretory, proliferative phase followed by endometrial hyperplasia. Though hysterectomy remained the last alternative in the treatment of abnormal uterine bleeding, it ensures complete relief to such patients and also the permanent cure of abnormal uterine bleeding.

Higher age and parity is a major risk factor associated with abnormal uterine bleeding, as parity and age increase the incidence of abnormal uterine bleeding is high in our study. Hypertension, Diabetes and chronic pelvic inflammatory diseases are also associated with abnormal uterine bleeding.

\section{Bibliography}

1. Awwad JT, Toth TL, Schiff I; Abnormal uterine bleeding in the Perimenopause. Int J Fertil Menopausal Stud., 1993; 38(5): 261-269.

2. Wren BG; Dysfunctional Uterine Bleeding. Aust Fam Physician, 1998; 27(5): 371-377.

3. Albers JR, Hull SK, Wesley MA; Abnormal uterine bleeding. Am Fam Phys., 2004; 69: 1915-1926.

4. Ely JW, Kennedy CM, Clark EC, Bowdler NC. Abnormal Uterine Bleeding: A Management Algorithm. J Am Board Fam Med 2006;19: 590-602.

5. Brandon JB, Amy EH,Nicholas CL, Harold EF, Edward EW; The Johns Hopkins Manual of Gynaecology and Obstetrics, 2nd edition, Philadelphia: Lippincott Williams \& Wilkins,2002: 405411.

6. ACOG Committee on Practice Bulletins-Gynecology. American College of Obstetricians and Gynecologists; ACOG practice bulletin: management of anovulatory bleeding. Int $\mathbf{J}$ Gynaecol Obstet. 2001;72(3), 263-271.

7. ACOG Practice Bulletin: Clinical Management of Anovulatory Bleeding. Int J Gynaecol Obstet 2001; 72(3): 263-71.

8. Dangal G. A study of endometrium of patients with abnormal uterine bleeding at Chitwan valley. KUMJ 2003;1:110-2.

9. Mutter GL: Diagnosis pf premalignant endometrial disease. J Clin Pathol, 2002; 55:326-331.

10. Zeeba S. Jairajpuri, S. Rana and S. Jetley Atypical uterine bleeding-Histopathological audit of endometrium $\mathrm{Al}$ Ameen $\mathrm{J}$ Med Sc i 2013; 6(1) :21-28 US National 
Library of Medicine enlisted journal ISSN 0974-1143.

11. Naheed Moghal (Department of Histopathology, Dubai Hospital, Department of Health and Medical Services, Dubai.) Diagnostic Value of Endometrial Curettage in Abnormal Uterine Bleeding - A Histopathological Study journal of Pakistan medical association dec 1997.

12. Yogesh Neena, Bhaskar Honey, "Clinicopathological correlation of hysterectomy specimens for abnormal uterine bleeding in rural area". Journal of Evolution of Medical and Dental Sciences 2013; Vol2, Issue 39, September 30; Page: 7506-7512.

13. Prasad Usha, Prasad Uma and K Rajani, Non - Secretory Endometrial Patterns in Cases of Abnormal Uterine Bleeding. RRJMHS Volume 3 Issue (Supplement 3) July - September, 2014.

14. Saraswathi Doraiswami, Thanka Johnson, Shalinee Rao, Aarthi Rajkumar, Jaya Vijayaraghavan, and Vinod Kumar Panicker Study of Endometrial Pathology in Abnormal Uterine Bleeding $\mathrm{J}$ Obstetrics Gynaecolgy India. Aug 2011; 61(4): 426430. Published online Sep 22, 2011.

15. Ayesha Sarwar and Anwar ul Haque Types and Frequencies of Pathologies in Endometrial Curettings of Abnormal Uterine Bleeding International Journal of Pathology; 2005; 3(2): 65-70.

16. Nadia Adnan Ghani Aiad Abdullah Abdulrazak Ehsan Mahmood Abdullah Abnormal Uterine Bleeding: a Histopathological Study Diyala Journal of Medicine 60 Vol. 4, Issue 1, April 2013.

17. Bhatta $S$ and Sinha AK Histopathological study of endometrium in abnormal uterine bleeding, Journal of Pathology of Nepal (2012) Vol. 2, 297-300.

18. Dr. Usha G. Doddamani and Dr. G.B. Doddamani, Dr.Geetanjali.Katageri , Dr.
Ashalata Mallapur, Clinicopathological Correlation of Endometrium in Abnormal Uterine Bleeding, Scholars Journal of Applied Medical Sciences (SJAMS)Sch. J. App. Med. Sci., 2014; 2(1A):46-49

19. Shakira Perveen, Subhana Tayyab; A Clinicopathological review of elective abdominal hysterectomy; Journal of Surgery Pakistan (International) 13 (1) January - March 2008.

20. Bhosle A,Fonseca M; Evaluation and histopathological correlation of Abnormal uterine bleeding in perimenopausal Women. Bombay Hospital Journal, 2010; 52(1): 69-72.

21. Shweta agrawal, asha mathur and kusum vaishnav histopathological study of endometrium in abnormal uterine bleeding in women of all age groups in western rajasthan $(400$ cases $) *$ International Journal of Basic and Applied Medical Sciences ISSN: $2277-2103$ (2014 Vol. 4 (3) September-December, pp. 15-18.

22. Ara S and Roohi M (2011). Abnormal uterine bleeding; histopathological diagnosis by conventional dilatation and curettage. Professional Medical Journal 18(4) 587-591.

23. Dr. Astha Saheta, Dr.C.Hariharan, Dr.Urvashi Sharma,Abnormal uterine bleeding ,IOSR Journal of Dental and Medical Sciences (IOSR-JDMS).Volume 13, Issue 11 Ver. II (Nov. 2014), PP 63-67. 24. Anupamasuresh Y, Suresh YV, Prachi Jain, Abnormal uterine bleeding: a clinicohistopathological analysis, Int $\mathbf{J}$ Reprod Contracept Obstet Gynecol . 2014; 3(3) : 656-661).

25. S Kayastha Study of endometrial tissue in Abnormal uterine bleeding Nepal Med Coll J 2013; 15(1): 27-30. 